\title{
molecules
}

ISSN 1420-3049

www.mdpi.com/journal/molecules

Review

\section{Azide-Alkyne Huisgen [3+2] Cycloaddition Using CuO Nanoparticles}

Hyunje Woo ${ }^{1}$, Hyuntae Kang ${ }^{1}$, Aram Kim ${ }^{1}$, Seongwan Jang ${ }^{1}$, Ji Chan Park ${ }^{2}$, Sungkyun Park ${ }^{3}$, Byeong-Su Kim ${ }^{4}$, Hyunjoon Song ${ }^{5}$ and Kang Hyun Park ${ }^{1, *}$

1 Department of Chemistry, Chemistry Institute for Functional Materials, Pusan National University, Busan 609-735, Korea

2 Clean Fuel Department, Korea Institute of Energy Research, Daejeon 305-343, Korea

3 Department of Physics, Pusan National University, Busan 609-735, Korea

4 Interdisciplinary School of Green Energy and School of NanoBioscience and Chemical Engineering, Ulsan National Institute of Science and Technology (UNIST), 100 Banyeon-ri, Ulsan 689-798, Korea

5 Department of Chemistry, Korea Advanced Institute of Science and Technology, Daejeon 305-701, Korea

* Author to whom correspondence should be addressed; E-Mail: chemistry@pusan.ac.kr; Tel.: +82-51-510-2238; Fax: +82-51-980-5200.

Received: 19 September 2012; in revised form: 29 October 2012 / Accepted: 1 November 2012 / Published: 6 November 2012

\begin{abstract}
Recent developments in the synthesis of $\mathrm{CuO}$ nanoparticles (NPs) and their application to the [3+2] cycloaddition of azides with terminal alkynes are reviewed. With respect to the importance of click chemistry, $\mathrm{CuO}$ hollow NPs, $\mathrm{CuO}$ hollow NPs on acetylene black, water-soluble double-hydrophilic block copolymer (DHBC) nanoreactors and $\mathrm{ZnO}-\mathrm{CuO}$ hybrid NPs were synthesized. Non-conventional energy sources such as microwaves and ultrasound were also applied to these click reactions, and good catalytic activity with high regioselectivity was observed. $\mathrm{CuO}$ hollow NPs on acetylene black can be recycled nine times without any loss of activity, and water-soluble DHBC nanoreactors have been developed for an environmentally friendly process.
\end{abstract}

Keywords: copper oxide; nanocatalyst; heterogeneous; hybrid; click reaction 


\section{Introduction}

Recently, metal oxide nanoparticles (NPs) have been used frequently as metal catalysts due to their high physical and chemical stability [1-4]. Their distinct qualities, particularly their large surface area, makes them applicable to a wide range of fields. Among the metal oxide NPs, copper oxides $\left(\mathrm{Cu}_{2} \mathrm{O}\right.$, $\mathrm{CuO}$ ) are p-type semiconductor materials with a small band gap energy. Recently, Tarascon's group used copper oxide $\left(\mathrm{Cu}_{2} \mathrm{O}, \mathrm{CuO}\right) \mathrm{NPs}$ as an anode material for lithium ion cells [5], while Izaki's group employed n-type semiconducting material ZnO NPs, for solar cell plates, thereby demonstrating their highly useful electrochemical characteristics [6]. In addition, copper oxide $\left(\mathrm{Cu}_{2} \mathrm{O}, \mathrm{CuO}\right) \mathrm{NPs}$ have sufficient space to adsorb harmful gases, as shown by their application as a gas sensor by Yadong's group [7]. Furthermore, $\mathrm{Cu}(\mathrm{II}) \mathrm{NPs}$ are non-toxic, environmentally friendly, highly stable, and recyclable. The research results presented here demonstrate the use of $\mathrm{Cu}$ (II) NPs for click chemistry. Click chemistry is a highly efficient cycloaddition method that became very popular as a new synthesis route since its introduction in 2001 by Sharpless [8]. This click chemistry concept as a wide scope, and it can be defined by the following criteria, high yield, modularity, readily available starting materials and reagents, and simple reaction conditions. The azide-alkyne Huisgen method, involving $\mathrm{Cu}(\mathrm{I})$-catalyzed cycloaddition between terminal acetylenes and azides at room temperature is one of the most efficient reactions within the concept of click chemistry [9-11]. The reaction proceeds in variable solvents in the presence of a catalyst and yields stable triazoles with possible applications in pharmaceuticals, DNA modification, and organic synthesis [12]. The commonly used catalysts in click reaction are $\mathrm{Cu}$ and $\mathrm{Ru}$. The $\mathrm{Cu}$ catalyst generates the 1,4-regioisomer, while Ru-based catalysis yields the 1,5-regioisomer (Scheme 1).

Scheme 1. Azide-alkyne [3+2] cycloaddition generating 1,4 and 1,5 regioisomer.

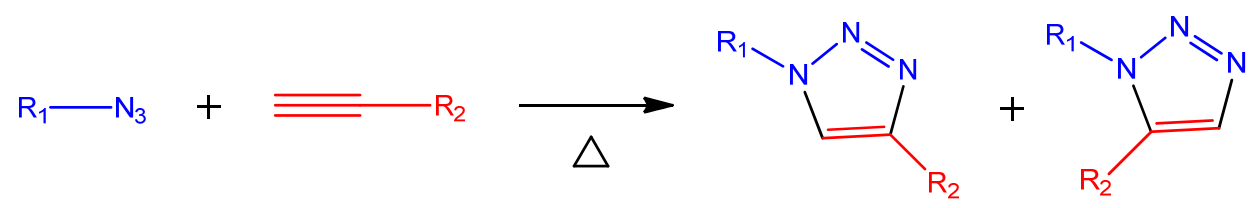

Recently, $\mathrm{CuO}$ NPs have been already used for the preparation of nucleosides in biochemistry and as a catalyst in azide-alkyne cycloadditions by other groups $[13,14]$. Other groups have also synthesized $\mathrm{CuO}$ NPs as a catalyst for CSe, CTe, and CS bond formation and synthesis of 2-aminobenzothiazoles $[15,16]$. To increase the surface area for enhancing the catalytic activity, $\mathrm{CuO}$ hollow NPs have been synthesized by using $\mathrm{Cu}_{2} \mathrm{O}$ nanocube colloidal solutions [17]. Due to the large surface area of the hollow nanostructures, this material was applied in click chemistry as a highly efficient catalyst. Previously, it was not possible to recover and recycle homogeneous catalysts which posed the greatest problem in the pharmaceutical field. In the present study, $\mathrm{CuO}$ hollow NPs were anchored onto acetylene black $(\mathrm{AB})$ in order to resolve the catalyst recovery problem [18]. In addition, the excitation of the reacting reagents by non-conventional energy sources such as microwaves and ultrasound represents well-known valuable techniques in organic chemistry. The use of these energy sources results in shorter reaction times compared to conventional heating [19]. Since the use of environmentally friendly substances has obvious ecological and economic advantages, performing click chemistry in aqueous media is becoming popular, but remains challenging [20-25]. Double-hydrophilic block 
copolymers (DHBCs), which consist of one active ionizable and one neutral block were used for the growth control of the inorganic phase. CuO NPs synthesized by using the DHBCs method, as well as hybrid nanostructures, were applied for ultrasound-assisted click chemistry [26]. The hybrid nanostructures exhibited the highest catalytic activity among conventional heterogeneous catalysts in ultrasound-assisted click chemistry [27] (Scheme 2).

Scheme 2. $[3+2]$ Cycloaddition of azides with terminal alkynes using various $\mathrm{CuO}$ nanocatalysts.

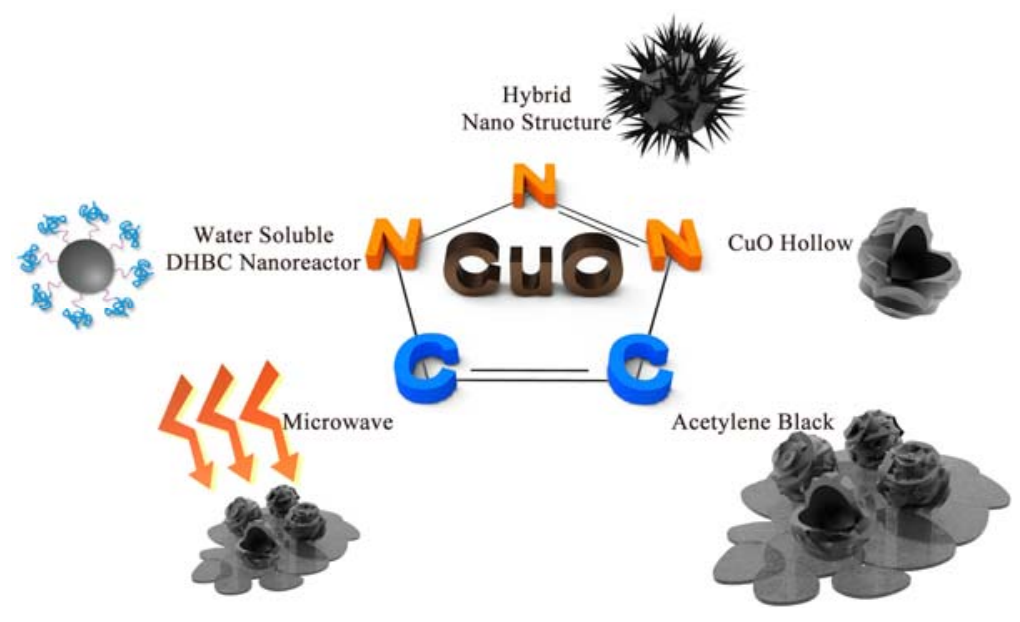

\section{Representative Experimental Methods}

\subsection{Preparation of $\mathrm{Cu}_{2} \mathrm{O}$ Nanocubes}

Poly(vinylpyrrolidone) (PVP, Aldrich, Mw 55,000; $5.3 \mathrm{~g}$ ) dissolved in 1,5-pentanediol (PD, Aldrich, $96 \%, 45 \mathrm{~mL}$ ) was heated to $240{ }^{\circ} \mathrm{C}$ under inert conditions. Then, $\mathrm{Cu}(\mathrm{acac})_{2}$ (STREM, 98\%, $4.0 \mathrm{mmol})$ dissolved in PD $(15 \mathrm{~mL})$ was injected into the hot PVP solution at $240{ }^{\circ} \mathrm{C}$, and the mixture was stirred for $15 \mathrm{~min}$ at the same temperature. The colloidal dispersion was cooled to room temperature, and the product was separated by adding acetone $(150 \mathrm{~mL})$ with centrifugation at $8,000 \mathrm{rpm}$ for $20 \mathrm{~min}$. The precipitates were washed with ethanol several times, and re-dispersed in ethanol $(50 \mathrm{~mL})$.

\subsection{Synthesis of $\mathrm{CuO}$ Hollow and Branched Nanostructures}

An appropriate concentration of aqueous ammonia solution was added into the $\mathrm{Cu}_{2} \mathrm{O}$ cube dispersion in ethanol $(25 \mathrm{~mL}, 16 \mathrm{mM}$ with respect to the precursor concentration). The mixture was subjected to stirring at room temperature for $2 \mathrm{~h}$. The volume and concentration of the aqueous ammonia solution used for each structure were $1.0 \mathrm{~mL}$ and $14.7 \mathrm{M}$ for hollow cubes, $2.0 \mathrm{~mL}$ and $7.36 \mathrm{M}$ for hollow spheres, and $6.0 \mathrm{~mL}$ and $2.45 \mathrm{M}$ for urchin-like particles, respectively. For shape optimization of the hollow spheres, a $3.68 \mathrm{M}$ aqueous ammonia solution was used. After the reaction, the products were collected by centrifugation at $6,000 \mathrm{rpm}$ for $20 \mathrm{~min}$. For the mechanism study, the appropriate amount of $\mathrm{NaOH}$ (Aldrich, 99.998\%) was dissolved in aqueous ammonia solution (14.7 M, $1.0 \mathrm{~mL})$. The resulting mixture was added to the ethanol dispersion of $\mathrm{Cu}_{2} \mathrm{O}$ cubes $(25 \mathrm{~mL}, 16 \mathrm{mM}$ with respect to the precursor concentration), and allowed to stir at room temperature for $2 \mathrm{~h}$. Hollow cubes were obtained without $\mathrm{NaOH}$. Addition of $\mathrm{NaOH}(20 \mathrm{mg}, 0.50 \mathrm{mmol}$ and $50 \mathrm{mg}, 1.3 \mathrm{mmol})$ yielded hollow spheres and urchin-like particles, respectively. 


\subsection{Immobilization of $\mathrm{CuO}$ Hollow Nanospheres on Acetylene Carbon Black (CuO/AB) and}

\section{Charcoal $(\mathrm{CuO} / \mathrm{C})$}

Acetylene carbon black (STREM, 99.99\%, $1.2 \mathrm{~g}$ ) was mixed with $\mathrm{CuO}$ hollow nanosphere dispersion in ethanol $(17.0 \mathrm{mM}, 100 \mathrm{~mL})$, and the reaction mixture sonicated for $1 \mathrm{~h}$ at room temperature. After $1 \mathrm{~h}$, the product $\mathrm{CuO} / \mathrm{AB}$ was washed with ethanol several times and vacuum dried at room temperature. For the synthesis of $\mathrm{CuO} / \mathrm{C}$, a mixed solution of charcoal $(0.8 \mathrm{~g})$ and $\mathrm{CuO}$ hollow nanosphere dispersion in ethanol $(50.0 \mathrm{mM}, 50.0 \mathrm{~mL})$ was refluxed for $4 \mathrm{~h}$. After $4 \mathrm{~h}$, the black suspension was cooled to room temperature and precipitated by centrifugation. The product $\mathrm{CuO} / \mathrm{C}$ was washed with ethanol thoroughly and dried in a vacuum oven at room temperature.

\subsection{Water-Soluble CuO NPS}

The $\mathrm{CuO}$ NPs were prepared according to the following protocols: first, double-hydrophilic block copolymer PEO(3500)-b-PAA(7500) (Polymer Source Inc, Montereal, Canada, $21.15 \mathrm{mg}, 0.20 \mathrm{mmol}$ carboxylic-acid groups) and copper chloride dihydrate $(17.8 \mathrm{mg}, 0.10 \mathrm{mmol})$ in water $(5.0 \mathrm{~mL})$ were separately prepared and mixed under vigorous stirring. $\mathrm{NaOH}(1.0 \mathrm{M}, 0.10 \mathrm{~mL}, 0.10 \mathrm{mmol})$ was added to this solution mixture, and a blue precipitate was obtained. Subsequently, 10.0 M hydrazine $(0.10 \mathrm{~mL}, 1.0 \mathrm{mmol})$ was added dropwise to the resulting suspensions under vigorous stirring. As soon as hydrazine was added, the solution turned orange. After $20 \mathrm{~min}$ of vigorous stirring, the reaction mixture kept still for $10 \mathrm{~min}$, after which the solution color changed to brownish red. The solution mixture was centrifuged to remove the large aggregates of particles therein (1,500 rpm, $15 \mathrm{~min}$ ), then the recovered supernatant was used as a catalyst for click chemistry.

\subsection{Synthesis of Polycrystalline ZnO Nanospheres}

A mixture of zinc(II) acetylacetonate hydrate $(0.10 \mathrm{~g}, 0.40 \mathrm{mmol})$ and PVP $(1.0 \mathrm{~g}, 9.0 \mathrm{mmol})$ was dissolved in PD $(40 \mathrm{~mL})$, and then slowly heated to $230{ }^{\circ} \mathrm{C}$ for $12 \mathrm{~min}$ under an inert condition. The mixture solution was allowed to stir at the same temperature for $3 \mathrm{~min}$. After that, the colloidal dispersion was cooled to room temperature, and the product was separated by adding ethanol (120 $\mathrm{mL})$ with centrifugation. The precipitates were washed with ethanol several times and re-dispersed in ethanol $(10 \mathrm{~mL})$.

\subsection{Synthesis of $\mathrm{ZnO} / \mathrm{Cu}_{2} \mathrm{O}$ Hybrid Nanoparticles}

A mixture of zinc(II) acetylacetonate hydrate $(0.10 \mathrm{~g}, 0.40 \mathrm{mmol})$ and PVP $(1.0 \mathrm{~g}, 9.0 \mathrm{mmol})$ was dissolved in PD $(40 \mathrm{~mL})$, and then slowly heated to $230^{\circ} \mathrm{C}$ for $12 \mathrm{~min}$ under an inert atmosphere. The mixture was allowed to stir at the same temperature for $3 \mathrm{~min}$. Then, $\mathrm{Cu}(\mathrm{acac})_{2}(0.1 \mathrm{~g}, 0.40 \mathrm{mmol})$ dissolved in PD $(5.0 \mathrm{~mL})$ was injected into the hot zinc-PVP mixture solution at $230{ }^{\circ} \mathrm{C}$ and the mixture was stirred for $10 \mathrm{~min}$ at the same temperature. The colloidal dispersion was cooled to room temperature, and the product was separated by adding ethanol $(120 \mathrm{~mL})$ with centrifugation. The precipitates were washed with ethanol several times and re-dispersed in ethanol (10 $\mathrm{mL})$. 


\subsection{Synthesis of $\mathrm{ZnO} / \mathrm{CuO}$ Core-Branch Nanoparticles}

An aqueous sodium hydroxide solution $(1.0 \mathrm{M}, 1.0 \mathrm{~mL})$ was added into $\mathrm{ZnO} / \mathrm{Cu}_{2} \mathrm{O}$ hybrid nanoparticle dispersion in ethanol $(25 \mathrm{~mL}, 8.0 \mathrm{mM}$ with respect to the precursor concentration). The mixture was subjected to stirring at room temperature for $1 \mathrm{~h}$. After the reaction, the product was collected by centrifugation. Finally, the particles were dispersed in ethanol.

\section{CuO Hollow Nanoparticles: [3+2] Cycloaddition of Azides with Terminal Alkynes}

In general, a $\mathrm{Cu}(\mathrm{I})$ salt is directly used as a catalyst. Alternatively, $\mathrm{Cu}(\mathrm{II})$ may be used after reduction [28-30]. This study shows the best results of click reactions using well-designed, uniform, hollow-structured $\mathrm{CuO}$ nanoparticles (Figure 1). An approach for the gram-scale synthesis of uniform $\mathrm{Cu}_{2} \mathrm{O}$ nanocubes by a one-pot polyol process was used [31]. CuO hollow NPs were prepared by adding aqueous ammonia solutions to $\mathrm{Cu}_{2} \mathrm{O}$ nanocube colloidal solutions.

Figure 1. TEM images of (a) $\mathrm{Cu}_{2} \mathrm{O}$ nanocube; (b) $\mathrm{CuO}$ hollow nanoparticles; (c) $\mathrm{CuO}$ hollow nanoparticles after click reaction; and (d) magnification of $\mathrm{CuO}$ hollow nanoparticles. The scale bars represent $200 \mathrm{~nm}, 200 \mathrm{~nm}, 100 \mathrm{~nm}, 50 \mathrm{~nm}$, respectively (a-d).

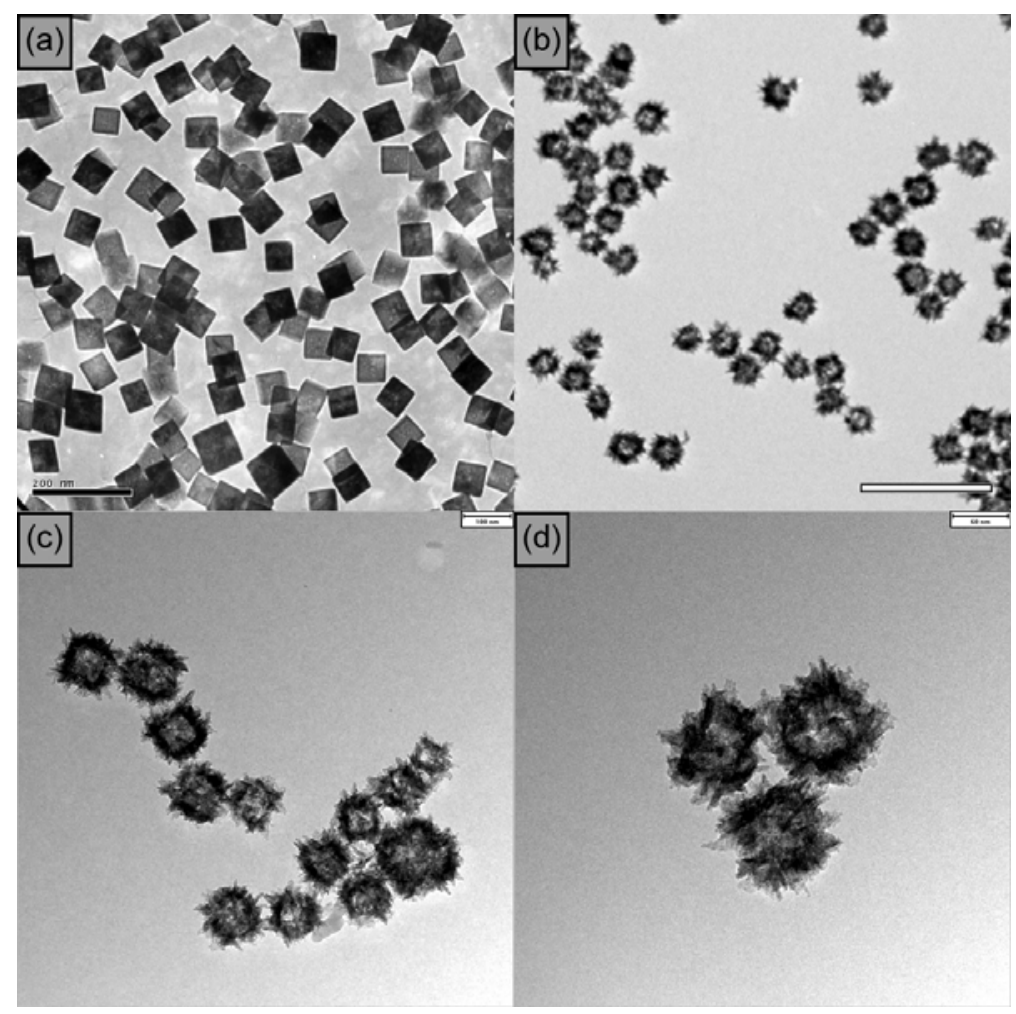

As shown in Table 1, several experiments were conducted in order to determine the solvent system most suitable for the catalyst. Considering the hygroscopic properties of THF, dioxane and toluene, it is expected that the reaction conditions will be affected by the amount of water present (entries 1-4, Table 1). Both $t$ - $\mathrm{BuOH}$ [32] and water as solvents gave high yields under mild conditions (entries 5 and 6), though the best results were obtained with a solvent mixture of $t-\mathrm{BuOH}$ and $\mathrm{H}_{2} \mathrm{O}(2: 1)$ (entry 4), which indicates that solubility and hygroscopic properties are comparably important factors. In case of using commercially available $\mathrm{CuO}$, a yield of less than $1 \%$ was found under the same 
conditions. Extending the reaction time to $24 \mathrm{~h}$, a yield of merely $35 \%$ was achieved (entries 7 and 8 ). Please note that even under optimum reaction conditions, no reaction occurred without catalyst (entries 9, Table 1).

Table 1. Optimization of click reaction catalyzed by various $\mathrm{CuO}(\mathrm{II})$ nanoparticles.

\begin{tabular}{cccccc}
\hline Entry & Cat (5 mol\%) & Temp $\left({ }^{\circ} \mathbf{C}\right)$ & Time (h) & Solvent & Conv. ${ }^{\text {a }}$ (\%) \\
\hline 1 & $\mathrm{CuO}$ urchins & 60 & 12 & $\mathrm{THF}-\mathrm{H}_{2} \mathrm{O}(24: 1)$ & 4 \\
2 & $\mathrm{CuO}$ urchins & 100 & 12 & Dioxane $/ \mathrm{H}_{2} \mathrm{O}(24: 1)$ & 61 \\
3 & $\mathrm{CuO}$ urchins & 110 & 12 & Toluene $/ \mathrm{H}_{2} \mathrm{O}(24: 1)$ & 93 \\
4 & $\mathrm{CuO}$ urchins & 25 & 3 & $\mathrm{H}_{2} \mathrm{O} / \mathrm{t}-\mathrm{BuOH}(2: 1)$ & 96 \\
5 & $\mathrm{CuO}$ urchins & 25 & 3 & $\mathrm{H}_{2} \mathrm{O}$ & 90 \\
6 & $\mathrm{CuO}$ urchins & 25 & 3 & $t-\mathrm{BuOH}$ & 71 \\
7 & Commercial $\mathrm{CuO}^{\mathrm{b}}$ & 25 & 24 & $\mathrm{H}_{2} \mathrm{O} / t-\mathrm{BuOH}(2: 1)$ & 35 \\
8 & Commercial $\mathrm{CuO}^{\mathrm{b}}$ & 25 & 3 & $\mathrm{H}_{2} \mathrm{O} / t-\mathrm{BuOH}(2: 1)$ & $<1$ \\
9 & - & 25 & 3 & $\mathrm{H}_{2} \mathrm{O} / t-\mathrm{BuOH}(2: 1)$ & 0 \\
10 & $\mathrm{CuO}$ urchins & 25 & 3 & $\mathrm{H}_{2} \mathrm{O} / t-\mathrm{BuOH}(2: 1)$ & $93^{\mathrm{c}}$ \\
11 & $\mathrm{CuO}$ hollow spheres & 25 & 3 & $\mathrm{H}_{2} \mathrm{O} / t-\mathrm{BuOH}(2: 1)$ & $100^{\mathrm{c}}$ \\
12 & $\mathrm{CuO}$ hollow cubes & 25 & 3 & $\mathrm{H}_{2} \mathrm{O} / t-\mathrm{BuOH}(2: 1)$ & $94^{\mathrm{c}}$ \\
$13^{\mathrm{d}}$ & $\mathrm{CuO}$ hollow spheres & 25 & 0.5 & $\mathrm{H}_{2} \mathrm{O} / t-\mathrm{BuOH}(2: 1)$ & 98 \\
\hline
\end{tabular}

Reaction Conditions: benzyl azide (1mmol) and phenylacetylene $(1.5 \mathrm{mmol})$ in $\mathrm{H}_{2} \mathrm{O}-t$-BuOH $(2: 1)$. ${ }^{\text {a }}$ Determined by ${ }^{1} \mathrm{H}-\mathrm{NMR}$ spectra; ${ }^{\mathrm{b}}$ Purchased from Aldrich (nanopowder, cat No. 544868); ${ }^{\mathrm{c}}$ Conversion based upon an average of two runs; ${ }^{\mathrm{d}}$ In the presence of 1.0 eq. $\mathrm{Et}_{3} \mathrm{~N}$.

Generally, decreasing size of the particles and increasing active surface area lead to enhanced catalytic activity. However, $\mathrm{CuO}$ hollow spheres showed a slightly better activity than hollow cubes, as shown in Table 1. The corresponding Brunauer-Emmett-Teller (BET) surface areas of the different $\mathrm{CuO}$ NPs measured by nitrogen sorption experiments are $79 \mathrm{~m}^{2} \mathrm{~g}^{-1}$ for hollow cubes, $113 \mathrm{~m}^{2} \mathrm{~g}^{-1}$ for hollowspheres, and $81 \mathrm{~m}^{2} \mathrm{~g}^{-1}$ for urchin-like particles. It is quite reasonable that the catalytic activities depend on the active surface areas of the catalysts. When $\mathrm{Et}_{3} \mathrm{~N}$ (1.0 eq.) was added, the reaction proceeded faster and was completed within 30 min (entry 13, Table 1). After cycloaddition, the $\mathrm{CuO}$ hollow nanospheres were separated by centrifugation and subsequently used in click reactions with phenylacetylene at least three times without loss in catalytic activity.

\section{Immobilized CuO Hollow Nanospheres in Alkyne-Azide Cycloadditions}

The impossibility in recovering and recycling homogeneous catalysts is a task of great economic and environmental importance in the chemical and pharmaceutical industries, especially when expensive and/or toxic heavy metal complexes are employed [33]. The development of catalysts anchored to solid supports has been one of the areas of most intense research activity over the past years. Acetylene black is a special type of carbon black formed by an exothermic decomposition of acetylene and is characterized by the highest degree of aggregation and crystalline orientation when compared with all types of carbon black. Acetylene black is widely used in battery systems possessing excellent electric conductivity, large specific surface areas and strong adsorptive abilities, as well as in supports [34]. 
The transmission electron microscopy (TEM) image in Figure 2a shows the regular shape of the $\mathrm{CuO}$ particles. $\mathrm{CuO}$ hollow spheres were obtained as highly monodisperse NPs with a size of $103 \pm 8 \mathrm{~nm}$. The crystalline features of the hollow spheres are represented in the XRD data (Figure 2d). The $\mathrm{CuO}$ hollow particles were immobilized on acetylene carbon black by simple sonication at room temperature. The TEM image in Figure $2 \mathrm{~b}$ shows that the immobilized $\mathrm{CuO}$ hollow spheres are well dispersed and isolated with approximately $100 \mathrm{~nm}$ average diameter, thus maintaining their original size and structure. As shown in Figure 2c, the structure of the $\mathrm{CuO}$ hollow NPs onto $\mathrm{AB}$ remained unchanged after the reaction, thereby demonstrating the recyclability of the catalyst [17].

Figure 2. TEM images of (a) $\mathrm{CuO}$ hollow nanoparticles; (b) $\mathrm{CuO}$ hollow nanoparticles on acetylene black; and after fifth cycle (c); (d) XRD spectra of $\mathrm{CuO}$ hollow nanoparticles on acetylene black. The scale bars represent $500 \mathrm{~nm}, 500 \mathrm{~nm}, 100 \mathrm{~nm}$, respectively (a-c).

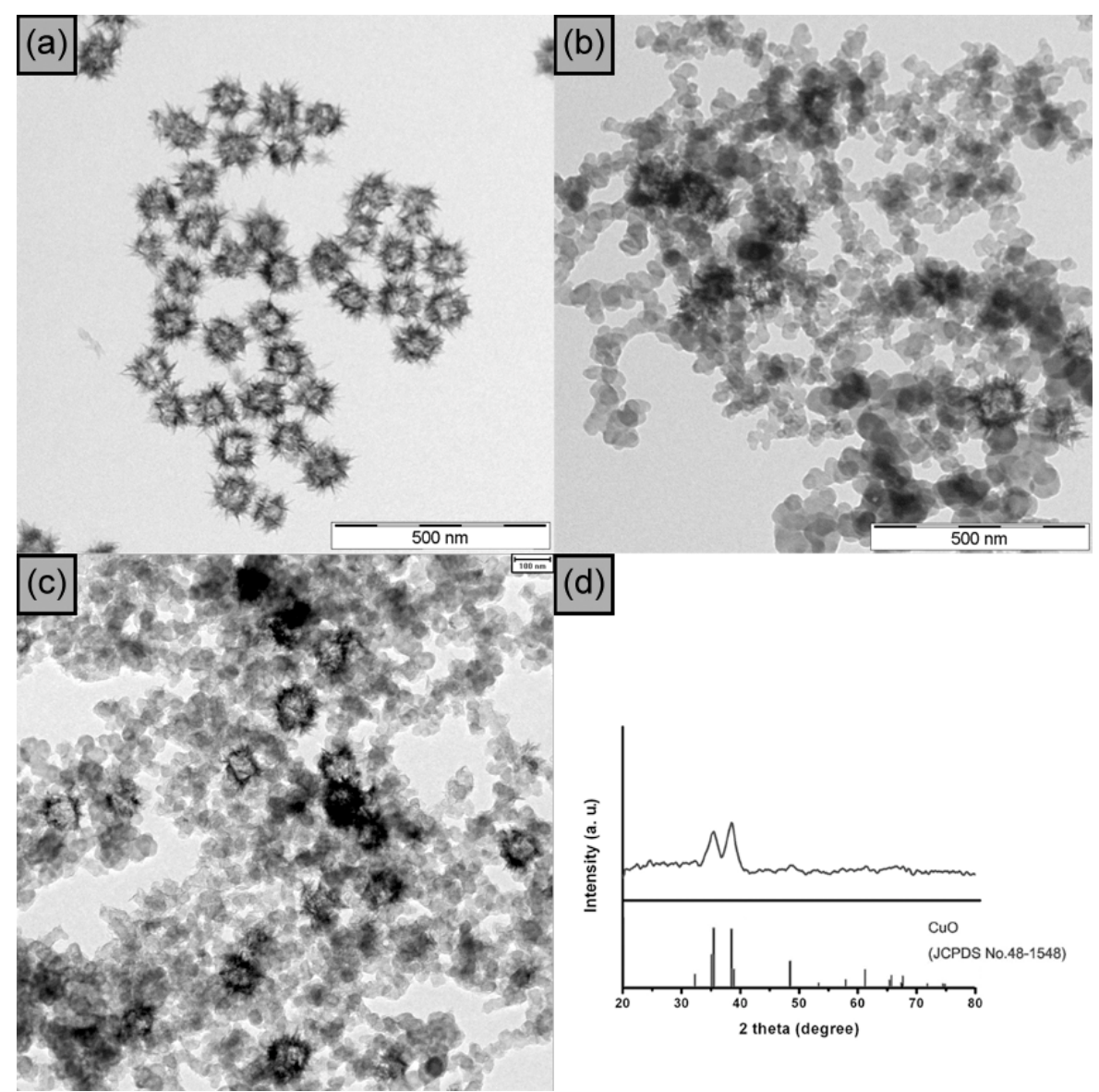

As shown in Table 2, the reaction was carried out at $25-50{ }^{\circ} \mathrm{C}$ using benzyl azide and phenylacetylene as the benchmark substrate. With respect to temperature and for $t$ - $\mathrm{BuOH}$ being the solvent, the best results were obtained at mild, room temperature conditions. The results could be further improved by replacing the pure solvents $t$ - $\mathrm{BuOH}$ and $\mathrm{H}_{2} \mathrm{O}$ by a corresponding mixture in the ratio $2: 1$, indicating that both solubility and hydroscopic properties are important factors.

Remarkably, after the reaction, the $\mathrm{CuO}$ NPs on $\mathrm{AB}$ were separated by centrifugation and could be reused up to nine times under the same reaction conditions without any loss of catalytic activity. An inductively coupled plasma-mass spectrometry (ICP-AES) study showed that the copper loss from the catalyst was negligible. These results confirm that the catalytic system presented here satisfies the 
conditions for heterogeneous catalysts with respect to easy separation, recyclability, and persistence. Moreover, these heterogeneous systems are promising industrial catalysts.

Table 2. Optimization of click reaction catalyzed by various $\mathrm{CuO}$ nanoparticles.

\begin{tabular}{ccccc}
\hline Entry & Cat (mol\%) & Temp $\left({ }^{\circ} \mathbf{C}\right)$ & Time $(\mathbf{h})$ & Conv (\%) ${ }^{\mathbf{a}}$ \\
\hline 1 & Blank & 50 & 5 & 7 \\
2 & CuO (5 mol\%) & 25 & 3 & 100 \\
3 & CuO on AB (1 mol\%) & 25 & 3 & $>1$ \\
4 & CuO on AB (1 mol\%) & 50 & 5 & 22 \\
5 & CuO on AB (3 mol\%) & 25 & 5 & $>1$ \\
6 & CuO on AB (3 mol\%) & 50 & 5 & 100 \\
7 & CuO on AB (3 mol\%) & 50 & 3 & 60 \\
8 & CuO on AB (3 mol\%) & 40 & 5 & 23 \\
9 & CuO on AB (3 mol\%) & 30 & 5 & 1.1 \\
10 & CuO on AB (5 mol\%) & 50 & 5 & 96 \\
11 & Recovered from \# 6 & 50 & 5 & 100 \\
12 & Recovered from \# 12 & 50 & 5 & 100 \\
13 & Recovered from \# 13 & 50 & 5 & 100 \\
14 & Recovered from \# 14 & 50 & 5 & 100 \\
15 & Recovered from \# 15 & 50 & 5 & 98 \\
16 & Recovered from \# 16 & 50 & 5 & 100 \\
17 & Recovered from \# 17 & 50 & 5 & 100 \\
18 & Recovered from \# 18 & 50 & 5 & 100 \\
19 & Recovered from \# 19 & 50 & 5 & 00 \\
\hline
\end{tabular}

Reaction conditions: benzyl azide $(0.84 \mathrm{mmol})$ and phenylacetylene $(1.18 \mathrm{mmol})$ in $\mathrm{H}_{2} \mathrm{O}-t-\mathrm{BuOH}(2: 1)$.

${ }^{a}$ Determined by ${ }^{1} \mathrm{H}-\mathrm{NMR}$. Yields are based on the amount of benzyl azide used.

\section{Solvent-Free Microwave Promoted [3+2] Cycloaddition of Alkyne-Azide}

Microwave-assisted organic synthesis (MAOS) has been highlighted as a very synthesis route due to the short reaction times in comparison to methods employing conventional heating [35-37]. Microwave activation with it non-conventional energy source is becoming a very popular and valuable technique in organic chemistry, as demonstrated by the annual publications on this topic, whose number is rapidly increasing. Thus, MAOS was employed for the chemical reactions presented herein (Scheme 3).

Scheme 3. Microwave-assisted solvent-free click reaction.
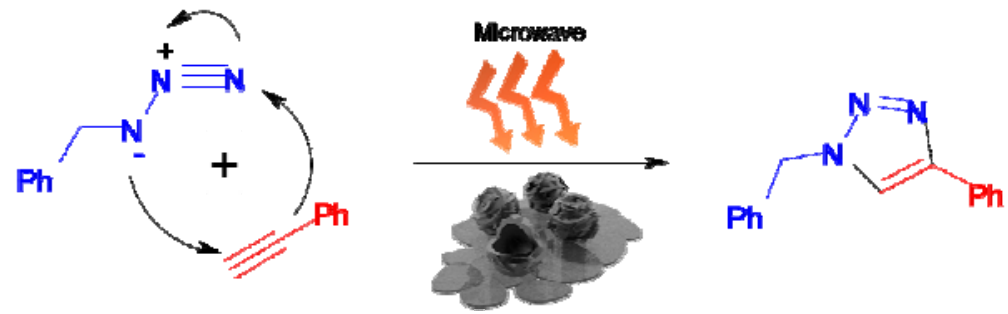
As shown in Table 3, several experiments were conducted in order to determine the solvent system that is most suitable for the catalyst. The $\mathrm{H}_{2} \mathrm{O} / t-\mathrm{BuOH}$ solvent system was employed to compare the synthesis by microwave activation and conventional heating. To complete the reaction by conventional heating, a reaction time of $5 \mathrm{~h}$ at $50{ }^{\circ} \mathrm{C}$ was required. When the temperature was increased to $100{ }^{\circ} \mathrm{C}$, a $91 \%$ conversion yield was obtained in $1 \mathrm{~h}$. The reaction time was shortened to $1 \mathrm{~min}$ with a high yield by using microwaves as energy source. When the reaction time was shortened to $30 \mathrm{~s}$, conversion was reduced to $13 \%$. As listed in Table 3, the use of different solvent results in different yields. Dimethyl sulfoxide (DMSO), a solvent in the high-ranking group with a large dielectric loss, showed a $100 \%$ conversion. Water, belonging to the middle group, showed a $28 \%$ conversion. Water has the highest dielectric constant, but its dielectric loss values $\varepsilon$ and angles tan $\delta$ do not rank at the top of their respective list. Considering only the dielectric constant, one would assume that water is the most polar solvent in a microwave field. However, due to the comparatively low dielectric loss values and angles, water should be classified as a medium absorber material. Upon conventional heating, a mixture of THF, toluene, $t-\mathrm{BuOH}$, and water gave a high yield due to specific hygroscopic properties [32]. Next, the reactivity in the $\mathrm{H}_{2} \mathrm{O} / \mathrm{t}$ - $\mathrm{BuOH}$ solvent system was examined in a series of experiments in which the quantity of the catalyst was changed. When the concentration of the catalyst was reduced to $1.0 \mathrm{~mol} \%$ and $0.5 \mathrm{~mol} \%$, a conversion of over $99 \%$ was obtained. At a catalyst concentration of $0.3 \mathrm{~mol} \%$, the conversion was reduced to $37 \%$. However, using DMSO, which has a larger, the reaction proceeded with only $0.3 \mathrm{~mol} \%$ of the catalyst. When the reaction time was reduced to $30 \mathrm{~s}$, the reaction proceeded smoothly, such that the quantity of the catalyst could be reduced to $0.1 \mathrm{~mol} \%$. Interestingly, when the reaction was carried out without a solvent (entry 16), the yield was dramatically improved to $100 \%$. Even when using a $0.1 \mathrm{~mol} \%$ catalyst, a satisfactory conversion of $96 \%$ was achieved (Table 3 ).

Table 3. Optimization of click reaction catalyzed by $\mathrm{CuO} / \mathrm{AB}$.

\begin{tabular}{ccccc}
\hline Entry & Cat (mol\%) & Time (min) & Solvent & Conv (\%) ${ }^{\mathbf{a}}$ \\
\hline 1 & 3 & 300 & $\mathrm{H}_{2} \mathrm{O} / t-\mathrm{BuOH}(2: 1)$ & $100^{\mathrm{b}}$ \\
2 & 3 & 60 & $\mathrm{H}_{2} \mathrm{O} / t-\mathrm{BuOH}(2: 1)$ & $91^{\mathrm{c}}$ \\
3 & 3 & 1 & $\mathrm{H}_{2} \mathrm{O} / t-\mathrm{BuOH}(2: 1)$ & 100 \\
4 & 3 & 0.5 & $\mathrm{H}_{2} \mathrm{O} / t-\mathrm{BuOH}(2: 1)$ & 10 \\
5 & 3 & 1 & $\mathrm{H}_{2} \mathrm{O}$ & 28 \\
6 & 3 & 1 & $t-\mathrm{BuOH}$ & 100 \\
7 & 3 & 1 & $\mathrm{DMSO}$ & 100 \\
8 & 3 & 1 & $\mathrm{DMF}$ & 100 \\
9 & 3 & 1 & $1-\mathrm{BuOH}$ & 100 \\
10 & 3 & 1 & $2-\mathrm{BuOH}$ & 11 \\
11 & 3 & 1 & $\mathrm{Toluene}$ & 0 \\
12 & 3 & 1 & $\mathrm{THF}$ & 0 \\
13 & 1 & 1 & $\mathrm{H}_{2} \mathrm{O} / t-\mathrm{BuOH}(2: 1)$ & $>99$ \\
14 & 0.5 & 1 & $\mathrm{H}_{2} \mathrm{O} / t-\mathrm{BuOH}(2: 1)$ & $>99$ \\
15 & 0.3 & 1 & $\mathrm{H}_{2} \mathrm{O} / t-\mathrm{BuOH}(2: 1)$ & 37 \\
16 & 0.3 & 1 & - & 100 \\
17 & 0.3 & 0.5 & - & 13 \\
18 & 0.1 & 1 & - & 96 \\
19 & 0.3 & 1 & $\mathrm{DMSO}$ & 100 \\
\hline
\end{tabular}


Table 3. Cont.

\begin{tabular}{ccccc}
\hline Entry & Cat (mol\%) & Time (min) & Solvent & Conv (\%) $^{\mathbf{a}}$ \\
\hline 20 & 0.3 & 0.5 & DMSO & 100 \\
21 & 0.1 & 1 & DMSO & 94 \\
22 & - & 1 & - & 3 \\
\hline
\end{tabular}

Reaction conditions: benzyl azide $(1 \mathrm{mmol})$ and phenylacetylene $(1.5 \mathrm{mmol}) .{ }^{a}$ Determined by ${ }^{1} \mathrm{H}-\mathrm{NMR}$. Yields are based on the amount of benzyl azide used; ${ }^{b}$ Conventional thermal heating at $50{ }^{\circ} \mathrm{C} ;{ }^{\mathrm{c}}$ Conventional thermal heating at $100^{\circ} \mathrm{C}$.

Good results were attained upon using various terminal alkynes (Table 4). When the phenyl group was directly linked to the reactive azide, phenyl azide gave the expected 1,4-diphenyl-1H-1,2,3triazole in the form of a single regioisomer with $100 \%$ conversion (entry 1, Table 4). Acetylenes, such as propynoic acid ethyl ester, reacted efficiently with the benzyl azide. The corresponding triazole, 1-benzyl-4-(phenoxymethyl)-1H-1,2,3-triazole, was relatively sluggish (entry 8 Table 4). The reaction with aliphatic alkynes, such as ethynyltrimethylsilane, gave high yields (entry 3, Table 4). Electrondonating or -withdrawing groups at the benzyl azides only slightly affected the reactivity [19]. $p$ - $\mathrm{Cl}$, $p$-methoxy, $o$-methoxy groups gave the expected 1-(4-chlorophenyl)-4-phenyl-1H-1,2,3-triazole, 1-(4methoxyphenyl)-4-phenyl-1H-1,2,3-triazole, and 1-(2-methoxyphenyl)-4-phenyl-1H-1,2,3-triazole in the form of single regioisomers with $88 \%, 85 \%$, and $75 \%$ conversions, respectively (entries 4 , 5, and 6 in Table 4). Use of alkynes containing electron-withdrawing substituents, such as ethyl propiolate, significantly altered the reactivity (entry 8 , Table 4). In some cases, electron-donating or -withdrawing groups on the benzyl azides greatly affected the reactivity. Electron-withdrawing groups impeded the reaction with corresponding lower yields. Among these groups, nitrogen dioxide in para position and OMe in ortho configuration exhibited the largest effect (entries 6 and 10, Table 4). Nevertheless, a single regioisomer was still produced, and yields of the products remained excellent.

\section{Water-Soluble Block Copolymer Nanoreactors for the Synthesis of CuO Nanoparticles and Their Application in Click Chemistry}

To date, a number of methods have been described to prepare $\mathrm{Cu}_{2} \mathrm{O}$ NPs with different particle size, morphology, and properties. The various preparation techniques include controlled thermal decomposition, chemical reduction with a proper surfactant, electrochemical reduction, microemulsion and the use of reverse micelles in a supercritical solvent. In all these methods, control of the particle size and morphology is achieved by the use of either a templating material or a capping reagent during NP growth.

Block copolymers have received much attention as attractive templates or scaffolds for engineering inorganic nanostructured materials, especially to control the size and spatial arrangement of NPs [38,39] (Scheme 4). Chemical activation by ultrasound, a nonconventional energy source, has become a very popular and useful technology in organic chemistry [40]. Several examples of ultrasound-assisted reactions have indicated high yields and short reaction times, and applications of this energy transfer process onto click reactions have been published [41]. However, performing click chemistry in aqueous media is still challenging due to the absence of a stable and active catalyst that is water-soluble [42]. Aqueous click chemistry has the economic, environmental, and processing benefits 
of both homogeneous aqueous catalysis and aqueous two phase catalysis. Water clearly stands out as the solvent of choice, with its fast reaction rate, high yield, selectivity, cheapness, "green" solvent nature, and environmental acceptability.

Table 4. Results for solvent-free microwave promoted [3+2] cycloaddition of various azides with terminal alkynes in the presence of $\mathrm{CuO} / \mathrm{AB}$.

Entry

${ }^{\mathrm{a}}$ Determined by ${ }^{1} \mathrm{H}-\mathrm{NMR}$. Yields are based on the amount of benzyl azide used.

Reaction conditions: azide ( $1 \mathrm{mmol})$ and acetylene $(1.5 \mathrm{mmol})$. 
Scheme 4. Ultrasound-assisted click reaction using water-soluble block copolymer nanoreactor.
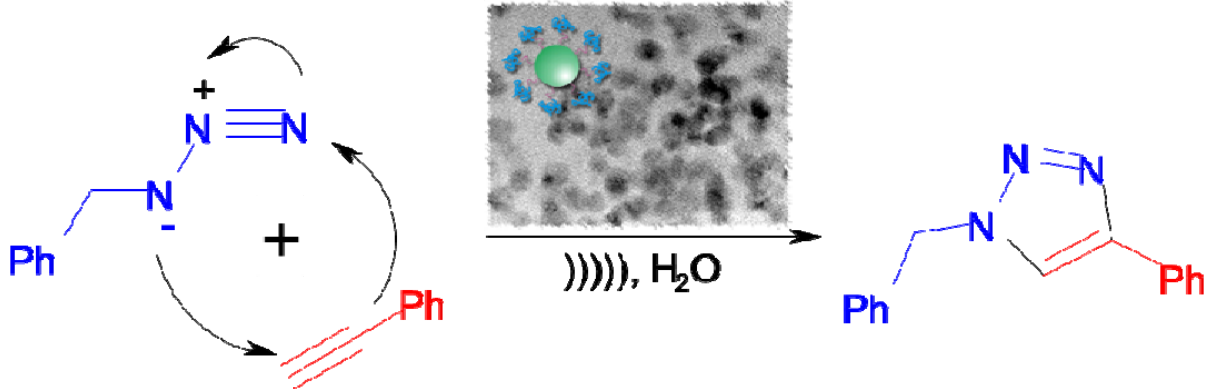

The original sizes and structures of the $\mathrm{CuO}$ NPs prepared by use of DHBC nanoreactors were preserved during catalytic transformations. The absolute amount of $\mathrm{Cu}$ that was used for click chemistry was determined by employing inductively coupled plasma optical-emission spectroscopy (ICP-OES). The CuO NPs within a DHBC shell showed excellent catalytic activity towards a wide range of azides and acetylenes.

Using water-soluble $\mathrm{CuO}$ nanoparticles (1 mol\%), 1-benzyl-4-phenyl-1H-1,2,3-triazole was obtained with more than $99 \%$ conversion within 10 min (entry 4, Table 5). In general, it was found that increasing the reaction temperature and time were effective means of increasing the conversion (entries 2 and 3, Table 5). Using water-soluble $\mathrm{CuO}$ NPs $(0.5 \mathrm{~mol} \%)$ as the catalyst was used, a yield of $38 \%$ was achieved under the same conditions (entry 6, Table 5). Remarkably, the water-soluble $\mathrm{CuO}$ NPs were separated via centrifugation after the reaction, and they could be reused three times without any catalytic activity loss under identical reaction conditions. These results confirm that water-soluble $\mathrm{CuO}$ NPs represent an alternative catalytic system that satisfies the conditions for heterogeneous catalysis (easy separation, recyclability, and persistence).

Table 5. Optimization of the click reaction catalyzed by water-soluble $\mathrm{CuO}$ nanoparticle.

\begin{tabular}{ccccc}
\hline Entry & Cat (mol \%) & Temp $\left({ }^{\circ} \mathbf{C}\right)$ & Time (h) & Conv. (\%) ${ }^{\text {a }}$ \\
\hline 1 & 1 mol\% CuO-poly & 25 & 3 & $3^{\text {b }}$ \\
2 & 1 mol\% CuO-poly & 50 & $10 \mathrm{~min}$ & 17 \\
3 & 1 mol\% CuO-poly & 100 & $5 \mathrm{~min}$ & 37 \\
4 & 1 mol\% CuO-poly & 100 & $10 \mathrm{~min}$ & $>99$ \\
5 & 1 mol\% CuO-poly & 100 & $10 \mathrm{~min}$ & $27^{\mathrm{c}}$ \\
6 & 0.5 mol\% CuO-poly & 100 & $10 \mathrm{~min}$ & 38 \\
7 & Recovered \# 4 & 100 & $10 \mathrm{~min}$ & 99 \\
8 & Recovered \# 7 & 100 & $10 \mathrm{~min}$ & 100 \\
\hline
\end{tabular}

Reaction conditions: benzyl azide $(0.80 \mathrm{mmol})$ and phenylacetylene $(1.18 \mathrm{mmol})$ in $\mathrm{H}_{2} \mathrm{O} 4.5 \mathrm{~mL}$.

a Determined by ${ }^{1} \mathrm{H}-\mathrm{NMR}$. Yields are based on the amount of benzyl azide used; ${ }^{\mathrm{b}}$ Transitional stirring;

${ }^{\mathrm{c}}$ Conventional thermal heating at $100{ }^{\circ} \mathrm{C}$.

\section{ZnO-CuO Core-Branch Nanocatalysts for Ultrasound-Assisted Click Reaction}

Hybrid NPs offer multi-functionality with synergistic effects of independent domains [43,44]. From the viewpoint of heterogeneous catalysis, these hybrid NPs could supply optimal architectures for bifunctional catalytic systems [45-47]. Simply stated, one of the components serves as an active 
surface for the reaction, while the other behaves as a support to stabilize the entire structure. The inorganic interface between the two components can either tailor the chemical nature of the active component or generate new species to enhance the catalytic activity.

In the present study, we combined the concepts of bifunctional catalysts and branched morphology in a colloidal metal-oxide system [27]. The $\mathrm{ZnO}-\mathrm{Cu}_{2} \mathrm{O}$ hybrid NPs were synthesized by reduction of a copper precursor onto polycrystalline $\mathrm{ZnO}$ spheres. The resulting hybrid structures, so-called $\mathrm{ZnO}-\mathrm{CuO}$ core-branch NPs, have active facets, and defects as well as large surface areas, and therefore, they are considered to be promising for catalytic applications. The $\mathrm{ZnO}-\mathrm{CuO}$ core-branch NPs were synthesized via a two-step process from $\mathrm{ZnO}$ nanospheres (Scheme 5).

Scheme 5. Synthetic scheme of $\mathrm{ZnO}-\mathrm{CuO}$ core-branch hybrid nanoparticles.
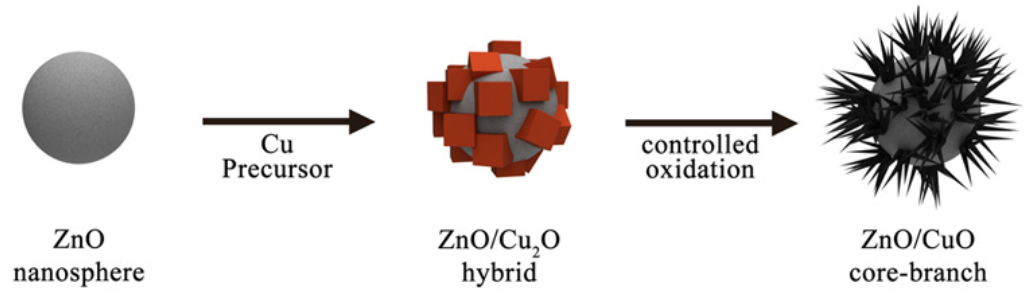

The TEM image in Figure $3 \mathrm{~b}$ shows that $\mathrm{Cu}_{2} \mathrm{O}$ nanocubes with an average edge size of $27 \pm 4 \mathrm{~nm}$ were attached on the $\mathrm{ZnO}$ surface. The XRD pattern is a combination of wurtzite $\mathrm{ZnO}$ and primitive cubic $\mathrm{Cu}_{2} \mathrm{O}$ reflections (Figure 3c, JCPDS No. 77-0199). The distance between neighboring lattice fringes in the HRTEM image is $0.21 \mathrm{~nm}$, in good agreement with the distance between $\{200\}$ crystallographic planes of the $\mathrm{Cu}_{2} \mathrm{O}$ phase. The TEM image shows needle-like $\mathrm{CuO}$ branches with an average length of $49 \pm 4 \mathrm{~nm}$ and a thickness of $8 \mathrm{~nm}$ (Figure 3a). Figure 3d shows the core-level x-ray photoelectron spectroscopy (XPS) spectra of $\mathrm{Cu} 2 \mathrm{p}_{3 / 2}$ of the $\mathrm{CuO} / \mathrm{ZnO} \mathrm{NPs}$ before and after the chemical reaction. The spectra were fitted after removing a Shirley background. The solid curves represent the best-fitting results. The XPS spectra can be deconvoluted into two peaks for both cases. The lower (higher) binding energy (BE) might be attributed to the $\mathrm{Cu} 2 \mathrm{p}_{3 / 2}$ state of $\mathrm{Cu}_{2} \mathrm{O}(\mathrm{CuO})$. After chemical reaction, the two peaks are shifted towards higher BE. However, the relative areal intensity ratio between $\mathrm{Cu}_{2} \mathrm{O}$ and $\mathrm{CuO}$ increased and reached the same, suggesting that the system changed into $\mathrm{Cu}_{2} \mathrm{O}$ after the chemical reaction. Any remaining $\mathrm{CuO}$ remaining might be due to the air-contamination during sample transport for the XPS measurements.

To demonstrate the prominence of the $\mathrm{ZnO}-\mathrm{CuO}$ core-branch NPs inorganic catalysis, the particles were employed as a heterogeneous catalyst for cycloaddition reactions of benzyl azide and phenylacetylene to yield 1,4-disubstituted 1,2,3-triazoles. The catalytic reactions were carried out in a mixed solvent of $\mathrm{H}_{2} \mathrm{O}$ and $t$ - $\mathrm{BuOH}(2: 1)$ at room temperature. The $\mathrm{ZnO}-\mathrm{CuO}$ nanocatalysts with a concentration of $3 \mathrm{~mol} \%$ exhibited a conversion yield of $47 \%$, under vigorous stirring for $3 \mathrm{~h}$. 
Figure 3. (a) $\mathrm{ZnO} / \mathrm{CuO}$ core-branch nanoparticles; (b) $\mathrm{TEM}$ images of $\mathrm{ZnO} / \mathrm{Cu}_{2} \mathrm{O}$ core-shell hybrid nanoparticles; (c) XRD spectra of $\mathrm{ZnO} / \mathrm{Cu}_{2} \mathrm{O}$ and $\mathrm{ZnO} / \mathrm{CuO}$ hybrid nanoparticles; (d) XSP spectra of $\mathrm{ZnO} / \mathrm{CuO}$ hybrid nanoparticles. (Color online) The core-level XPS spectra of $\mathrm{Cu} 2 \mathrm{p}_{3 / 2}$ before and after chemical reaction. The solid curves represent the best-fitted results. The scale bars represent $200 \mathrm{~nm}(\mathbf{a}, \mathbf{b})$.

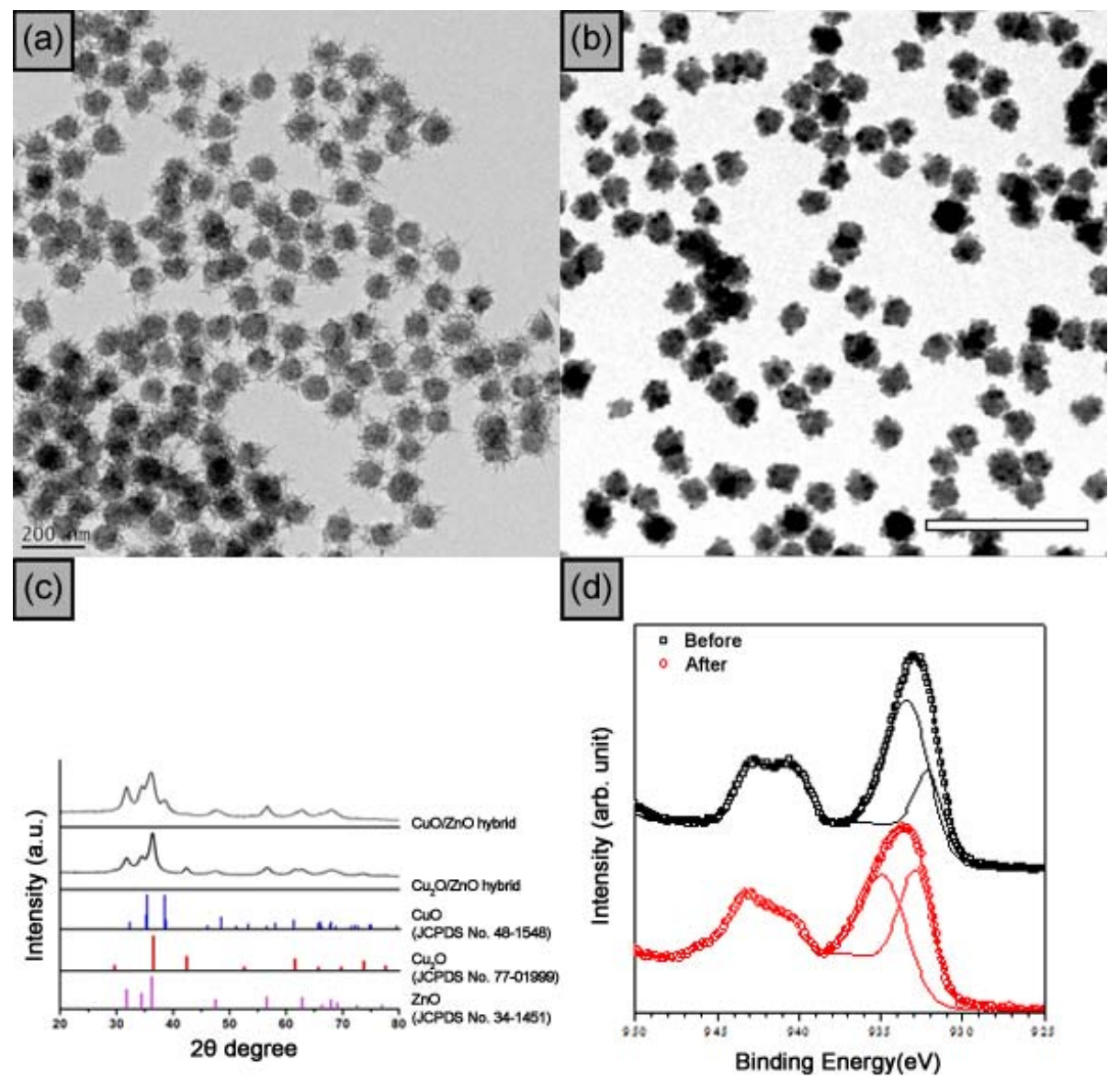

Notably, the catalytic performance was largely enhanced by applying ultrasound (Table 6). Ultrasound irradiation has been widely used in synthetic chemistry to induce mechanical effects on heterogeneous reactions [40]. Under the present reaction conditions with a $\mathrm{ZnO}-\mathrm{CuO}$ nanocatalyst, under ultrasound irradiation, the yield increased to complete conversion within $10 \mathrm{~min}$ at room temperature (entry 2, Table 6). The reaction did not proceed without ultrasound. CuO hollow nanospheres, one of the best catalysts among $\mathrm{Cu}$-based heterogeneous systems [17,19], activated the reaction with a yield of $14 \%$, whereas commercially available $\mathrm{mm}$-sized $\mathrm{CuO}$ particles proceeded the reaction with a yield of $1 \%$ under identical conditions (entries 5 and 6, Table 6). After the reaction, the $\mathrm{ZnO}-\mathrm{CuO} \mathrm{NPs}$ were readily recovered by centrifugation and were reused five times with only a slight loss of their catalytic activity (entries 8-12, Table 6). 
Table 6. $[3+2]$ Azide-alkyne cycloaddition reactions catalyzed by the $\mathrm{ZnO}-\mathrm{CuO}$ hybrid nanocatalysts under ultrasonic irradiation ${ }^{\mathrm{a}}$.

\begin{tabular}{|c|c|c|c|c|}
\hline Entry & Cat (mol\%) & Time (min) & Temp. & Conv. $^{\mathrm{b}}(\%)$ \\
\hline 1 & $\mathrm{ZnO}-\mathrm{CuO}(3 \mathrm{~mol} \%)$ & 5 & R. T. & 80 \\
\hline 2 & $\mathrm{ZnO}-\mathrm{CuO}(3 \mathrm{~mol} \%)$ & 10 & R. T. & 100 \\
\hline 3 & $\mathrm{ZnO}-\mathrm{CuO}(1 \mathrm{~mol} \%)$ & 10 & R. T. & 21 \\
\hline 4 & $\mathrm{ZnO}$ nanoparticles (3 mol\%) & 10 & R. T. & N.R. \\
\hline 5 & $\mathrm{CuO}$ hollows (3 mol\%) & 10 & R. T. & 14 \\
\hline 6 & Commercial $\mathrm{CuO}^{\mathrm{c}}(3 \mathrm{~mol} \%)$ & 10 & R. T. & $<1$ \\
\hline 7 & $\mathrm{ZnO}-\mathrm{Cu}_{2} \mathrm{O}(3 \mathrm{~mol} \%)$ & 10 & R. T. & 31 \\
\hline 8 & Recovered from \#2 & 10 & R. T. & 100 \\
\hline 9 & Recovered from \#8 & 10 & R. T. & 100 \\
\hline 10 & Recovered from \#9 & 10 & R. T. & 100 \\
\hline 11 & Recovered from \#10 & 10 & R. T. & 82 \\
\hline 12 & Recovered from \#11 & 10 & R. T. & 76 \\
\hline
\end{tabular}

${ }^{\mathrm{a}}$ Reaction conditions: benzyl azide $(0.6 \mathrm{mmol})$ and phenylacetylene $(0.9 \mathrm{mmol})$ in $\mathrm{H}_{2} \mathrm{O}-t-\mathrm{BuOH}(2: 1)$;

${ }^{\mathrm{b}}$ Determined by ${ }^{1} \mathrm{H}-\mathrm{NMR}$ spectra; ${ }^{\mathrm{c}} \mathrm{Commercial} \mathrm{CuO}$ purchased from Aldrich (cat. no. 544868).

\section{Conclusions}

We have synthesized various $\mathrm{CuO}$ NPs, specifically $\mathrm{CuO}$ hollow nanospheres, $\mathrm{CuO}$ hollow NPs on $\mathrm{AB}, \mathrm{DHBC}$ nanoreactors for the synthesis of $\mathrm{CuO}$ nanoparticles and $\mathrm{ZnO}-\mathrm{CuO}$ hybrid $\mathrm{NPs}$, and we have used non-conventional energy sources like microwaves and ultrasound with the aim of achieving $[3+2]$ cycloaddition of azides with terminal alkynes. The reaction products are predictably and reliably obtained, showing in all cases the exclusive formation of the 1,4-isomer.

$\mathrm{CuO}$ hollow NPs have shown a good catalytic activity. We have additionally loaded this catalyst onto $\mathrm{AB}$ to solve the recovery problem. The recycling of catalysts will give positive economical and environmental effect. Solvent-free microwave irradiation also exhibited good conversion yield in click reactions. Since organic synthesis in aqueous media is more challenging, we synthesized water-soluble DHBC nanoreactors for the synthesis of $\mathrm{CuO}$ NPs and performed ultrasound-assisted click reactions. The use of water as the solvent results in a high reaction rate, yield, and selectivity. Furthermore, it is cheap, and environmentally friendly. Synergistic effects between $\mathrm{ZnO}$ and $\mathrm{CuO}$ domains could be observed in $\mathrm{ZnO}-\mathrm{CuO}$ hybrid NPs with a high activity and reusability. We expect to produce good catalytic systems for many reactions, including click reactions.

\section{Acknowledgements}

This work was supported by Basic Science Research Program (2010-0026167, 2010-0002834), and the Ministry of Education, Science Technology (MEST) and National Research Foundation of Korea (NRF) through the Human Resource Training Project for Regional Innovation. K.H.P thank to the TJ Park Junior Faculty Fellowship.

\section{References}

1. Burda, C.; Chen, X.B.; Narayanan, R.; El-Sayed, M.A. Chemistry and Properties of Nanocrystals of Different Shapes. Chem. Rev. 2005, 105, 1025-1102. 
2. Kim, A.Y.; Lee, H.J.; Park, J.C.; Kang, H.; Yang, H.; Song, H.; Park, K.H. Highly Efficient and Reusable Copper-Catalyzed N-Arylation of Nitrogen-Containing Heterocycles with Aryl Halides. Molecules 2009, 14, 5169-5178.

3. Lin, K.-S.; Pan, C.-Y.; Chowdhury, S.; Tu, M.-T.; Hong, W.-T.; Yeh, C.-T. Hydrogen Generation Using a $\mathrm{CuO} / \mathrm{ZnO}-\mathrm{ZrO}_{2}$ Nanocatalyst for Autothermal Reforming of Methanol in a Microchannel Reactor. Molecules 2011, 16, 348-366.

4. Monopoli, A.; Nacci, A.; Calò, V.; Ciminale, F.; Cotugno, P.; Mangone, A.; Giannossa, L.C.; Azzone, P.; Cioffi, N. Palladium/Zirconium Oxide Nanocomposite as a Highly Recyclable Catalyst for C-C Coupling Reactions in Water. Molecules 2010, 15, 4511-4525.

5. Poizot, P.; Laruelle, S.; Grugeon, S.; Dupont, L.; Tarascon, J.-M. Nano-sized transition-metal oxides as negative-electrode materials for lithium-ion batteries. Nature 2000, 407, 496-498.

6. Izaki, M.; Shinagawa, T.; Mizuno, K.; Ida, Y.; Inaba, M.; Tasaka, A. Electrochemically constructed $\mathrm{p}-\mathrm{Cu} 2 \mathrm{O} / \mathrm{n}-\mathrm{ZnO}$ heterojunction diode for photovoltaic device. J. Phys. D Appl. Phys. 2007, 40, 3326-3329.

7. Zhang, J.; Liu, J.; Peng, Q.; Wang, X.; Li, Y. Nearly Monodisperse $\mathrm{Cu}_{2} \mathrm{O}$ and $\mathrm{CuO}$ Nanospheres: Preparation and Applications for Sensitive Gas Sensors. Chem. Mater. 2006, 18, 867-871.

8. Kolb, H.C.; Finn, M.G.; Sharpless, K.B. Click Chemistry: Diverse Chemical Function from a Few Good Reactions. Angew. Chem. Int. Ed. 2001, 40, 2004-2021.

9. Tornoe, C.W.; Christensen, C.; Meldal, M. Peptidotriazoles on Solid Phase: [1,2,3]-Triazoles by Regiospecific Copper(I)-Catalyzed 1,3-Dipolar Cycloadditions of Terminal Alkynes to Azides. J. Org. Chem. 2002, 67, 3057-3064.

10. Rostovtsev, V.V.; Green, L.G.; Fokin, V.V.; Sharpless, K.B. A Stepwise Huisgen Cycloaddition Process: Copper(I)-Catalyzed Regioselective "Ligation" of Azides and Terminal Alkynes. Angew. Chem. Int. Ed. 2002, 41, 2596-2599.

11. Meldal, M.; Tornøe, C.W. Cu-Catalyzed Azide-Alkyne Cycloaddition. Chem. Rev. 2008, 108, 2952-3015.

12. Moses, J.E.; Moorhouse, A.D. The growing applications of click chemistry. Chem. Soc. Rev. 2007, $36,1249-1262$.

13. Elayadi, H.; Ali, M.A.; Mehdi, A.; Lazrek, H.B. Nanoscrystalline CuO: Synthesis and application as an efficient catalyst for the preparation of 1,2,3-triazole acyclic nucleosides via 1,3-dipolar cycloaddition. Catal. Commun. 2012, 26, 155-158.

14. Molteni, G.; Bianchi, C.L.; Marinoni, G.; Santo, N.; Ponti, A. Cu/Cu-oxide nanoparticles as catalyst in the "click" azide-alkyne cycloaddition. New J. Chem. 2006, 30, 1137-1139.

15. Botteselle, G.V.; Godoi, M.; Galetto, F.Z.; Bettanin, L.; Singh, D.; Rodrigues, O.E.D.; Braga, A.L. Microwave-assisted one-pot synthesis of symmetrical diselenides, Ditellurides and disulfides from organoyl iodides and elemental chalcogen catalyzed by $\mathrm{CuO}$ nanoparticles. J. Mol. Catal. A 2012, 365, 186-193.

16. Rout, S.K.; Guin, S.; Nath, J.; Patel, B.K. An "on-water" exploration of CuO nanoparticle catalysed synthesis of 2-aminobenzothiazoles. Green Chem. 2012, 14, 2491-2498.

17. Kim, J.Y.; Park, J.C.; Kang, H.; Song, H.; Park, K.H. CuO hollow nanostructures catalyze [3 + 2] cycloaddition of azides with terminal alkynes. Chem. Commun. 2010, 46, 439-441. 
18. Kang, H.; Jung, H.S.; Kim, J.Y.; Park, J.C.; Kim, M.; Song, H.; Park, K.H. Immobilized CuO Hollow Nanospheres Catalyzed Alkyne-Azide Cycloadditions. J. Nanosci. Nanotechnol. 2010, 10, 6504-6509.

19. Kang, H.; Lee, H.J.; Park, J.C.; Song, H.; Park, K.H. Solvent-Free Microwave Promoted [3+2] Cycloaddition of Alkyne-Azide in Uniform CuO Hollow Nanospheres. Top Catal. 2010, 53, 523-528.

20. Kantam, M.L.; Jaya, V.S.; Sreedhar, B.; Rao, M.M.; Choudary, B.M. Preparation of alumina supported copper nanoparticles and their application in the synthesis of 1,2,3-triazoles. J. Mol. Catal. A Chem. 2006, 256, 273-277.

21. Sharghi, H.; Khalifeh, R.; Doroodmand, M.M. Copper Nanoparticles on Charcoal for Multicomponent Catalytic Synthesis of 1,2,3-Triazole Derivatives from Benzyl Halides or Alkyl Halides, Terminal Alkynes and Sodium Azide in Water as a "Green" Solvent. Adv. Synth. Catal. 2009, 351, 207-218.

22. Zhang, Z.; Dong, C.; Yang, C.; Hu, D.; Long, J.; Wang, L.; Li, H.; Chen, Y.; Kong, D. Stabilized Copper(I) Oxide Nanoparticles Catalyze Azide-Alkyne Click Reactions in Water. Adv. Synth. Catal. 2010, 352, 1600-1604.

23. Alonso, F.; Moglie, Y.; Radivoy, G.; Yus, M. Multicomponent Synthesis of 1,2,3-Triazoles in Water Catalyzed by Copper Nanoparticles on Activated Carbon. Adv. Synth. Catal. 2010, 352, 3208-3214.

24. Alonso, F.; Moglie, Y.; Radivoy, G.; Yus, M. Click chemistry from organic halides, Diazonium salts and anilines in water catalysed by copper nanoparticles on activated carbon. Org. Biomol. Chem. 2011, 9, 6385-6395.

25. Alonso, F.; Moglie, Y.; Radivoy, G.; Yus, M. Multicomponent Click Synthesis of 1,2,3-Triazoles from Epoxides in Water Catalyzed by Copper Nanoparticles on Activated Carbon. J. Org. Chem. 2011, 76, 8394-8405.

26. Kim, A.; Sharma, B.; Kim, B.-S.; Park, K.H. Double-Hydrophilic Block Copolymer Nanoreactor for the Synthesis of Copper Nanoparticles and for Application in Click Chemistry. J. Nanosci. Nanotechnol. 2011, 11, 6162-6166.

27. Park, J.C.; Kim, A.Y.; Kim, J.Y.; Park, S.; Park, K.H.; Song, H. ZnO-CuO core-branch nanocatalysts for ultrasound-assisted azide-alkyne cycloaddition reactions. Chem. Commun. 2012, $48,8484-8486$.

28. Lee, L.V.; Michaell, L.; Huang, S.J.; Fokin, V.V.; Sharpless, K.B.; Wong, C.H. A Potent and Highly Selective Inhibitor of Human $\alpha-1,3$-Fucosyltransferase via Click Chemistry. J. Am. Chem. Soc. 2003, 125, 9588-9589.

29. Appukkuttan, P.; Dehaen, W.; Fokin, V.V.; Eycken, V. A Microwave-Assisted Click Chemistry Synthesis of 1,4-Disubstituted 1,2,3-Triazoles via a Copper(I)-Catalyzed Three-Component Reaction. Org. Lett. 2004, 6, 4223-4225.

30. Feldman, A.K.; Colasson, B.; Fokin, V.V. One-Pot Synthesis of 1,4-Disubstituted 1,2,3-Triazoles from In Situ Generated Azides. Org. Lett. 2004, 6, 3897-3899.

31. Park, J.C.; Kim, J.; Kwon, H.; Song, H. Gram-Scale Synthesis of $\mathrm{Cu}_{2} \mathrm{O}$ Nanocubes and Subsequent Oxidation to $\mathrm{CuO}$ Hollow Nanostructures for Lithium-Ion Battery Anode Materials. Adv. Mater. 2009, 21, 803-807. 
32. Orgueira, H.A.; Fokas, D.; Isome, Y.; Chan, P.C.; Baldino, C.M. Regioselective synthesis of $[1,2,3]$-triazoles catalyzed by $\mathrm{Cu}(\mathrm{I})$ generated in situ from $\mathrm{Cu}(0)$ nanosize activated powder and amine hydrochloride salts. Tetrahedron Lett. 2005, 46, 2911-2914.

33. Hamilton, D.J.C. Homogeneous Catalysis--New Approaches to Catalyst Separation, Recovery, and Recycling. Science 2003, 299, 1702-1706.

34. Li, W.Y.; Li, C.S.; Zhou, C.Y.; Ma, H.; Chen, J. Metallic Magnesium Nano/Mesoscale Structures: Their Shape-Controlled Preparation and Mg/Air Battery Applications. Angew. Chem. Int. Ed. 2006, 45, 6009-6012.

35. Perreux, L.; Loupy, A. A tentative rationalization of microwave effects in organic synthesis according to the reaction medium, and mechanistic considerations. Tetrahedron 2001, 57, 9199-9223.

36. Gupta, G.K.; Rani, N.; Kumar, V. Microwave assisted synthesis of imidazoles-A review. Mini-Rev. Org. Chem. 2012, 9, 270-284.

37. Ullah, F.; Zang, Q.; Javed, S.; Porubsky, P.; Neuenswander, B.; Lushington, G.H.; Hanson, P.R.; Organ, M.G. Synthesis of an isoindoline-annulated, Tricyclic sultam library via microwaveassisted, continuous-flow organic synthesis (MACOS). Synthesis 2012, 44, 2547-2554.

38. Hamley, I.W. Nanotechnology with Soft Materials. Angew. Chem. Int. Ed. 2003, 42, 1692-1712.

39. Basina, G.; Mountrichas, G.; Devlin, E.; Boukos, N.; Niarchos, D.; Petridis, D.; Pispas, S.; Tzitzios, V. Synthesis and Magnetic Properties of $\mathrm{Fe}_{3} \mathrm{O}_{4}$ Nanoparticles Coated with Biocompatible Double Hydrophilic Block Copolymer. J. Nanosci. Nanotechnol. 2009, 9, 4753-4759.

40. Zhang, Z.; Zha, Z.; Gan, C.; Pan, C.; Zhou, Y.; Wang, Z.; Zhou, M. Catalysis and Regioselectivity of the Aqueous Heck Reaction by $\operatorname{Pd}(0)$ Nanoparticles under Ultrasonic Irradiation. J. Org. Chem. 2006, 71, 4339-4342.

41. Cintas, P.; Barge, A.; Tagliapietra, S.; Boffa, L.; Cravotto, G. Alkyne-azide click reaction catalyzed by metallic copper under ultrasound. Nat. Protoc. 2010, 5, 607-616.

42. Wang, Z.X.; Qin, H.L. Regioselective synthesis of 1,2,3-triazole derivatives via 1,3-dipolar cycloaddition reactions in water. Chem. Commun. 2003, 39, 2450-2451.

43. Zhang, J.; Tang, Y.; Lee, K.; Ouyang, M. Nonepitaxial Growth of Hybrid Core-Shell Nanostructures with Large Lattice Mismatches. Science 2010, 327, 1634-1638.

44. Casavola, M.; Buonsanti, R.; Caputo, G.; Cozzoli, P.D. Colloidal Strategies for Preparing Oxide-Based Hybrid Nanocrystals. Eur. J. Inorg. Chem. 2008, 6, 837-854.

45. Somorjai, G.A.; Park, J.Y. Colloid Science of Metal Nanoparticle Catalysts in 2D and 3D Structures, Challenges of Nucleation, Growth, Composition, Particle Shape, Size Control and Their Influence on Activity and Selectivity. Top. Catal. 2008, 49, 126-135.

46. Rolison, D.R. Catalytic Nanoarchitectures--the Importance of Nothing and the Unimportance of Periodicity. Science 2003, 299, 1698-1701.

47. Joo, S.H.; Park, J.Y.; Tsung, C.-K.; Yamada, Y.; Yang, P.; Somorjai, G.A. Thermally stable $\mathrm{Pt} /$ mesoporous silica core-shell nanocatalysts for high-temperature reactions. Nat. Mater. 2009, 8 , $126-131$.

(C) 2012 by the authors; licensee MDPI, Basel, Switzerland. This article is an open access article distributed under the terms and conditions of the Creative Commons Attribution license (http://creativecommons.org/licenses/by/3.0/). 